cally fallacious. The idea of an engine worked by the expansion of nitrogen under the influence of heat was fallacious in principle and practically impossible. A gentleman in the body of the room said he had listened to the paper with great interest, and regretted that it had not been allowed to be concluded. This remark was received with applause by the andience, and still greater applause followed when the author said, in retiring, that time would show whether the President or the principle was right. It seems clear that, having heen accepted by the Committee of the Section, and the title of it placed upon the programme of business, the paper was entitled to be read. We are glad to lay a short abstract of the "burked" parer bcfore our readers, expressing no opinion, further than that opinion should not be stifled.

The principle of the engine is as follows:-Crude nitrogen gas is heated in a serpentine system of tubes until the pressure is double that of the air. It is then admitted into a cylinder in which it presses forward a piston, and is allowed to expand. Next it passes into an apparatus where it is cooled, and consequently diminished to half its bulk. The cooling is effected in a new arrangement, which is so constructed that the whole of the heat above that of the external air is transferred to an equivalent volume of air passing in an opposite direction. This lieated air is then used as a blast for the fire, $\frac{1}{13}$ going to the hearth of the furnace through a tuyere, and ${ }^{4}$ mixing with the products of combustion immediately above the fire, so as to complete any imperfect combustion, and also to modify the temperature of the whole mass, so that it may not be likely to injure the jron of the gas tubes, and the remaining $\frac{5}{10}$ being introduced into the system at a point further on. The construction of the system of tubes is such that, by the time the products of combustion reach the open air, they shall have parted with nearly all their heat, and translerred it to the nitrogen contained in the tubes, and hence a chimney dratught cannot be used, and the blast has to be pro. duced by a blowing engine. The nitrogen, after having been cooled to half the volume it occupied in the first cylinder, is then compressed and forced into the system of tubes at the point furthest from the fire. It is this forcing the gas back again into the system of heating tubes that appears absurd; but it must be remembered that the gas while leaving the heating tubes occupies twice the space it does when being forced back, hence it fills a cylinder of twice the area, and the force that may now be disposed of is equal to half the pressure exerted in the larger cylinder. But the other half of the power is not lost, it is simply conveyed back to the heating tube, and is used again. The only losses that can arise are those which are incidental to all engines, such as radiation, conduction, \&c., inasmuch as there is avoided the enormous loss of heat that usually goes up the chimney, together with the still greater loss that is constantly being carried away by the condensed water,-an amount in itself six times as great as that converted into work in the steamengine. The inventor considers that he does not expect too much if he expects his new heat engine to convert 60 per cent. of the heat of combustion into work, a duty that is fully 500 fer cent. above that of well-constructed steam-engines.

Of course, as the author was not permitted to finish the reading of his paper, no discussion was taken upon it.

\section{REPORTS OF COMMITTEES}

THIRD REPORT OF UNDERGRUUND TEMPERATURE COMMITTEE

Mr. G. J. Symons, whose observations, extending to a depth of $I, 100$ feet in a well at Kentish Town, were reported at last meeting, has since repeated his observations at several depths.

The first 2 IO feet of the well (which is eight feet in diameter to the depth of 540 feet) are occupied by air, and in this portion of the well the second series of observations give temperatures exceeding those observed in the first series by from $2^{\circ}$ to $5^{\circ}$, the excess diminishing as the depth increases. The second series were taken in July and August, whereas the first series were taken in January. It is evident thet, in this portion of the well, in spite of the precautions taken to exclude atmospheric influences, by boarding over the well and erecting a hut over it, the temperature varies with the seasons, the variations being in the same direction as in the external air, but smaller, and diminishing as the depth increases, but still amounting to $2^{\circ} \cdot 2$ at the depth of 2 co feet.

We can feel no certainty that even the mean annual temperature in this portion of the well represents the temperature in the solid ground. On the contrary, the mean temperature in the well at any depth is probably intermediate between the temperature of the solid ground at that depth and the mean temperature of the external air.

It is well that such observations should have been carefully made and recorded in this ore instance, if only for the sake of warning; and they show that we cannot expect to attain the object for which the committee has been appointed hy observations in large shafts filled with air.

Mr. Symons has also repeated the obeervations at 250 feet (which is 40 feet under water), and at the depths of 600 feet, 750 feet, and every fiftieth foot from this to I, IoO feet, which is the lowest point attainable on account of the mud, which extends 300 feet lower. The differcnces from the results obtained last year are $+2,-3,-\cdot 4,-2,-2,0,-1,-\cdot 1,0$; which, uron the whole, strongly confirm the correctness of the observations.

The temperafure at $\mathbf{r}, 100$ feet is $69^{\prime} 8$, which, if we assume the mean temperature of the surface of the ground to he $\left\{\begin{array}{l}\left.50^{\circ}\right\} \\ 49^{\circ}\end{array}\right\}$, gives a mean increase downwards of $\left\{\begin{array}{c}0180 \\ \text { or } 89\end{array}\right\}$ of a degree Fabrenheit per font, or $\mathbf{1}^{\circ}$ for $\left\{\begin{array}{l}55.5 \\ 52.9\end{array}\right\}$ feet.

The curve in which temperature is the ordinate and depth the abscissa, exhibits considerahle irregularities till we reach the dep'h of 650 feet, beyond which it is nearly a straight line, and represents an increase of 0187 of a degree per foot.

The strata penetrated by the well to the depth to which our observations extend, consist of clay, sand, chalk, and marl, hesides fints. (See tabular list appended.)

Mr. Svmons, in his report, calls attention to the anomalous position of a column of watcr, increasing in temperature and, consequently, diminishing in specific gravity downwarcis, and suggests the inquiry why the warmer and lighter portions do not ascend to the top. The proper reply seems to be that the diminution of specific gravity, amounting to less than one part in 50,000 per vertical foot, does not furnish sufficient force to over. come liquid adhesion, and the water is thus able to remain in unstahle equilibrium.

Mr. Symons intends during the remainder of the present year, verifying those of his observations which have not yet been re peated, and concludes his report by remarking that it appears desirable to ascertain by observations from year to year, whether the temperature at a given depth (say 1,ono feet) remains constant or is subject to minute changes, periodical or otherwisea suggestion which appears fully worthy of being carried out.

Mr. Wm. Bryham, manager of Rosebridge Colliery, Ince, near. Wigan, has taken very valuable observations during the sinking of that colliery, which is now the deepest excavation in Great Britain. The principal results have already been given in a paper to the Royal Society by Mr. Edward Hull, director of the Geological Survey of Ireland, who had previously published some important contributions to our knowledge of underground temperature, and has now consented to become a member of this committee. Some of the depths have however been remeasured since Mr. Hull's paper was read, and we are now enabled, through the kindness of Mr. Bryham, to furnish a rather mo:e accurate report.

The temperatures observed, and the depths at which they were taken, are as follows:-

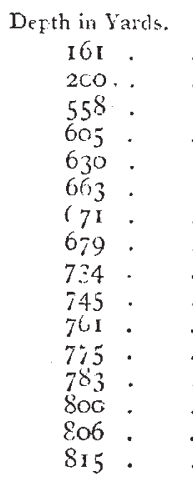

$$
\begin{array}{cc}
\text { Temperature Fahrenhcit. } \\
. & \left(64 \frac{1}{2}\right) \\
: & (1.6) \\
. & 78 \\
. & 80 \\
. & 83 \\
. & 85 \\
. & 86 \\
. & 87 \\
. & 85 ! \\
. & 89 \\
. & 90 \frac{1}{2} \\
. & 91 \frac{1}{2} \\
. & 92 \\
. & 93 \\
. & 93^{\frac{1}{3}}
\end{array}
$$

All these temperatures, except the two first, were observed during the sinking of the shaft, by drilling a hole with water, to the clepth of a yard, in the solid strata at the bottom. A 
thermometer was then inserted, the hole was tightly plugged with clay so as to be air-tight, and was left undisturbed for half an hour, at the end of which time the thermometer was withdrawn and read-a mode of observation which appears well adapted to give reliabie results. With respect to the temperaturs at 161 and 230 yards (which are enciosel in brackets to indicate uncertanty), Mr. Bryham says that he has some doubt as to the correctness of the thermometer $\mathrm{w}$.ith which they were taken, and that they were not taken in the shaft at the time it was sunk, lut in the seams at the depths named.

Asuming the surface temperature to be $49^{\circ}$, we have, on the whole dipth of 815 yards, or 2,445 feet, an increase of $45^{\circ}$, which is at the rate of $\mathrm{OI}_{4}$ of a degree per foot, or a degree for every $54: 3$ feet.

On plotting the temperature curve, including the two observa. tions m.uked as doubtful, we find that it natuially divides itself into four portions, which are approxinately straight lines.

The must remarkable of these portions is the second from the top, extending Irom the depth of 16I yards to that of 605 yards. It embraces $I, 332$ feet, and shows an increase of only $I^{\circ}$ for every 86 feet.

The third portion, extending from the depth of 605 yards to that of 671 yards, covers only 198 feet, and shows an incre sse of

$I^{\circ}$ for every 33 feet.

The lowest portion extends from the depth of $67 \mathrm{I}$ yards to $8 \mathrm{I} 5$ yards. It covers 432 feet, and shows an increase of $1^{\circ}$ in 54 feet.

The topmost portion will be affected by the assumption we make as to surface temperature. Assuming this as $49^{\circ}$, it shows an increase of $1^{\circ}$ in 31 feet.

It is interesting to compare the Rosebridge observations with those previously made by Mr. Fairbairn at Astley Pit, Dukin. field, Cheshire, which have been described by Mr. Hull in "The Coalfields of Great Britain," and by Mr. Fairbairn himself in the B. A. Report for 1861 . The results have been thus summed up by Mr. Hull :-

I. The first observation gives $5 \mathrm{I}^{\circ}$ as the invariable temperature throushout the year at the depth of 17 feet. Between 23 I yards and 270 yards the temperature was nearly uniform at $5^{\circ} \circ$. And the increase from the surface would be at the rate of $\mathbf{I}^{\circ} \mathrm{F}$. for 88 feet.

2. Between 270 and 309 yards, the increase was at the rate of $I^{\circ}$ for $62 \% 4$ feet.

3. Between 309 and 419 yards, the increase was at the rate of 1 for 60 feet.

4. Between 419 and 613 yards, the increase was at the rate of $1^{\circ}$ for $86{ }^{\circ} 91$ feet.

5. Between 613 and 685 yards, the increase was at the rate of $1^{\circ}$ for $65^{\circ} 6$ feet.

The result of the whole series of observations gives an increase of $\mathbf{I}^{\circ}$. for every $83 \cdot 2$ feet.

Mr. Fairbairn's own summary is as follows:- "The amount of inc-ease indicated in these experiments is from $51^{\circ} 1057^{\frac{3}{4}}$, as the clepth increases from $5^{\frac{2}{3}}$ yards to $23 \mathrm{I}$ yards, or an increase of $1^{\circ}$ in 99 feet. But if we take the results which are more reliable, namely, those between the depths of 231 and 685 yards, ve ha ic an increase of temperature from $57 \frac{3}{4}^{\circ}$ to $75^{\frac{1}{2}}$, or $17 \frac{3}{4}^{\circ}$ Fahrenheit. That is a mean increase of $I^{\circ}$ in 76.8 feet."

Mr. Fairbairn here, by implication, throws doubt on the alleged invariabie temperature of $5 \mathrm{i}^{\circ}$ at the depth of 17 feet, a dic.ernination which in itself appears highly improbable, seeing that at Greenwich the thermometer, whose bulb is buried at a depth of $25^{\circ} 6$ feet, exhibits an ammual range of $3^{\circ} \cdot 2$, while that at the depth of 12.8 feet exhibits a range of $9^{\circ}$. But even if we assume the mean surface teminerature to be $49^{\circ}$, we have still upon the whole depth an increase at the rate of $1^{\circ}$ in 80 feet, as against $1^{\circ}$ in 54.3 feet at Rosebridge.

Mr. Fairbairn's paper gives also the results obtained at a second pit at Dukinfield, which agree with those in the first in showing an exceptionally slow rate of increase downwards. The temperatures at the depths of $167 \frac{1}{2}$ yards and 467 yards were respectively $58^{\circ}$ and $661_{2}^{\circ}$, showing a difference of $8 \frac{1}{2}^{\circ}$ in $299 \frac{1}{2}$ yards, which is at the rate of $I^{\circ}$ in 106 feet. The increase from the surface down to $\times 67^{\frac{1}{2}}$ yards, assuming the surface temperature as $49^{\circ}$, would be $9^{\circ}$, or $1^{\circ}$ in 56 feet, and the mean rate of increase from the surface to the bottom would be $I^{\circ}$ in 80 feet, the same as in the first pit.

A tabular list of the strata at Rosebridge is appended to this report. A full account of the strata at Dukinfield is given in Mr. Fairbairn's paper (B.A. Report, 186I).

With strata so nearly similar and in two neighbouring counties, we should scarcely have expected so much difference in the mean rates of increase downwards. In this respect, Rosebridge agrees well with the average of results obtained elsewhere. Dukinfield far surpasses all other deep mines or wells, so far as our present records extend, in slowness of increase.

This implies one of two things, either that the strata of Dukinfield afford unusual facilities for the transmission of heat, or that the isothermal surfaces at still greater depths dip down in the vicinity of Dukinfield.

Mrr. Hull has called attention to a circumstance which favours the first of these explanations, the steepiness of inclination of the Dukinfield strata. He argues, with much appearance of probability, that beds of very various character (sandstones, shales, clays, and coal), alternating with each other, must offer more resistance to the transmission of heat across than parallel to their planes of bedding, as Mr. Hopkins has shown that every sudden change of material is equivalent to an increase of resistance; and it is obvious that highly inclined strata furnish a path by which heat can travel obliquely upwards without being interrupted by these breaches of continuity.

To this suggestion of Mr. Hull's it may be added that inclined strata furnish great facilities for the convection of heat by the flow of water along the planes of junction. It appears likely that surface water, by soaking downwards in this direction, may exercise an important influence in assimilating the temperature at great depths to that which prevails near the surface. Mr. Hull's own statement of his views is given in the foot-note below. *

Mr. McFarlane has been prevented from continuing his ob. servations near Glasgow during the past year by the press of business incident to the removal from the old to the new college.

Mr. F. Amery, Druid House, Ashburton, Devon, has taken some observations with one of the Committee's thermometers in the shaft of a mine which had been unused for a year, and was nearly full of water. The shaft is $12 \mathrm{ft} . \times 7 \mathrm{ft}$, and descends vertically for 350 ft., after which it slopes to the south at an angle of $50^{\circ}$, continuing to the depth of $620 .{ }^{\circ}$. The viater stood at 5 oft. from the surface. Mr. Nnery observed the temperature at every 5oth foot of depth in the vertical portion, and found it to be $53^{\circ}$ at all depths, except at $250 \mathrm{ft}$. and $200 \mathrm{ft}$., where it was 53.4 and $53^{\prime 2}$ respectively. A copper lude crosses the shaft at the depth of 250 .t. ; and it appears to be generally the case in the Cornwall and Devonshire nines, that copper lodes exhibit a high temperature, a circumstance which l'rof. Phillips explains by the conformation of the strata, which is such as to cause water from greater depths to malie its way obliquely up. wards by following the course of the copper lodes.

The nearly constant temperature observed from the surface to the bottom of the shaft seems to indicate a large amount of convective circulation. In this respect small bores have a decided advantage

Mr. G. A. Lebour has taken observations with one of our thermometers in several shafts and bores near Ridsdale, Northumberland, made for working coal and ironstone. Mr. Lebour does not report the temperatures observed, which he characterises as discrepant and utterly valueless, owing, he believes, to the numerous water-bearing beds which they cut through, and the very varying temperature of these waters. Having now, however, found a dry bure, he hopes to make a useful series of observations next winter.

* "Rosebridge Colliery occupies a position in the centre of a gently. sloping trough, where the beds are nearly borizontal; they are terminated both on the west and east by large parailel faults, which throw up the strata both on the west and east by large parailel faults, which throw up the strata
on either side. The colliery is placed in what is known as "the deep belt." "Dukinfield Colliery, on the other hand, is planted upon strata which are highly inclined. The beds of sandstone, shale, and coal rise and crop out to the eastward at angles varying from $30^{\circ}$ to $33^{\circ}$. Now, I think we may assume that strata consisting of sanditones, shales, clays, and coal alternating with each other, are capable of conducting heat more rapidly along the planes of bedding than across them, different kinds of rock having, as Mr. Hopkins's experiments show, different cunducting powers. If this be so, we have an evident reason for the dissimilar results in the case before us. Assuming a constant supply of heat from the interior of the earth, it could only escape, in the case of Rosebridge, across the planes of bedding, meeting in its progress upwards the resistance offered by strata of, in each case, varying conducting powers. On the other hand, in the case of Dukinfield, the interna heat could travel along the steeply-inclined strata themselves, and ultimately escape along the outcrop of the beds.

"I merely offer this as a suggestion explanatory of the results before us, and may be allowed to add that the strata at Monkwearmouth Colliery, the thermometrical observations at which correspond so closely with those obtained at Rosebridge, are also in a position not much removed from the horizontal, which is some evidence ia corroboration of the views here offered."-Proc. Roy. Soc., Jan. 27,1870 
One of the Committee's thermometers has recently been sent to Mr. John Donaldson, C.E., Calcutta, who has expressed his desire to aid in scientific observation, and being now engaged in examining for coal and iron under Government, is likely to render us effective service.

Shortly after the last meeting of the Association, the secretary of this committee addressed a letter to Prof. Hemy, secrelary of the Smithsonian Institution, U.S., requesting his co-opera. tion in furthering the object which the committee have in view, at the same time forwarding one of our protected thermometers.

In June of the present year an answer was received from Prof Baird, assistant secretary in charge, to the effect that Prof. Henry's ill-health during the present season had prevented his communicating to us the results of his labours in response to request.

The letter addressed to Prof. Henry made special reference to an artesian well of extraordinary depth which was understood to be in course of sinking at St. Louis, and at the same time a letter was addressed, and is special thermometer sent, to $\mathrm{Mr}$. C. W. Atkeson, the superintendent of the work of boring at St. Lotis. No reply has been received from $\mathrm{Mr}$. Alkeson, who appears to have left St. Louis before the letter arrived; but letters have been received through the Smithsonian Institution from Dr. Chas. W. Stevens, superintendent of the County Insane Asylum at St. Louis, this being the institution for whose uses the well was sunk, together with a very interesting newspaper cutting, consisting of $\mathrm{Mr}$. Atkeson's report on the works. The boring of the well was commenced (at the bottom of a dug well $71 \frac{1}{2}$ feet deep) on the 3ist of March, I866, and was continued till the gth of August, I 869, when the work was stopped at the enormous depth of $3,843^{\frac{1}{2}}$ feet, exceeding by more than one-half the depth of Dukinfiek Collery. The strata penetrated consisted in the aggregate of 63 feet of clay, 6 feet of coal, 380 feet of shales, 2,725 feet of limestone, and 620 fect of sandstone.

$A$ cast-iron tube of $\mathrm{I} J \frac{1}{2}$ inches bore was first put down, reachin $x$ from the top and secured in the limestone at the bottom. This tube was then lined inside with a wooden tube, reducing

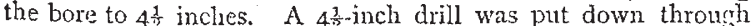
this tube on the above-mentioned date. The bore was afterwards enlarged to 6 inches, and subsequently to $1 \frac{1}{2}$ inches to a depth of $13 \mathrm{r}^{1}$ feet. A sheet-iron tube was then put down, extending from the top to this depth, and the bore below was enlarged, first to 6 and afterwards to to inches diamenter, to the depth of 953 feet. A sheet-iron tube, 79 feet long, was then put down, which rests on the offset at the bottom of the ro-inch bore. The $4^{2}$-inch bore was then cnlarged to 6 inches to the depth of 1,022 feet, and a wronght-iron tule of 5 inches bore, weighing more than six tons, was introduced, reaching from the top and resting on the offset at the bottom of the 6-inch bore, thus securing the work to this depth, and reducing the bore to convenient size to work in. The $4 \frac{1}{5}$-inch bore has been continued to the depth of 3,843 feet 6 inches without further tubing.

At the depth of 3,029 feet the first observation of temperature was taken, and the reading of the thermometer was $107^{\circ} \mathrm{F}$. This first observation is stated by Dr. Stevens to be specially worthy of confidence, as having been confirmed by several repetitions, or rather, to use Dr. Stevens's own worls, "this was the maximum of several trials." It was taken, as weil as those that followed it, by means of a registering thernometer (kind not mentioned); but in answer to our inquiries, Dr. Stevens states, upon the authority of the carpenter who attached the thermometer to the pole by which it was lowered, "that no means were taken to defend the bulb from pressure." In the absence of further information (and Mr. Atkeson himself has not yet spoken), we can place no reliance upon the temperatuxe recorded, as the thermoneter had to bear a pressure of $\frac{b}{b}$ of a mile. of waler.

The temperatures registered at lower depths, the deepest being 8 o feet lower, were all, strange to say, somewhat lower than this, a circumstance which is all the more remarkable because the pressure (which tends to make the reading higher) must have increased with the depth. At the bottom, or rather at 3,837 feet, being $6 \frac{1}{2}$ feet from the bottom, the temperature indicated was $105^{\prime 2}$. Either of these results, taken apart from the other and compared with the surface temperature, would give a result not improbable in itsclf. The mean temperature of the air at St. Louis appears to be about $53^{\circ}$, but it seems clesirable to avoid publishing calculations till the data are better established.

Unfortunately, the apparatus which was employed in boring has all bcen removed, after the insertion of two wooden plugs, with an iron screw at the upper end of each, one at the offset at a depth of 1,022 feet, and the other at the offset at the depth of 953 feet, for the purpose of separating the fresh from the salt waters. These plugs were driven in with great force, and can only be withdrawn with the aid of a series of poles and other appliances, such as were used in the boring, which will be rather costly. The poles alone are estimated to cost $1, \mathbf{1} 52$ dols., or about $200 \%$. If the plugs were withdrawn-and, according to $D$ r. Stevens, there is nothing but the expense to prevent-the whole well would be available for observation. The committee will make every effort to prevent so rare an opportunity from being lost.

The Secretary has also been in correspondence with Messrs. Mather and Platt, of Salford Iron Works, respecting a boring at Moscow, for which they have furnished machinery, and which is to be carried to the depth of 3,000 feet. They refer to General Helmerson, of the Mining College, St. Petersburg, as the best anthority to whom application can be made for particulars of the Moscow boring as to temperature, \&c. The secretaxy has accordingly written to General Helmerson, endeavouring to in terest him in the objects of the committee, and offering to for ward thermometers. No reply has yet been received.

An element which it is necessary to know, with a view to the correct reduction of our observations, but which in many in stances it is difficult to obtain by direct observation, is the mean annual temperature of the ground, at or near the surface. Instances frequently occur in which the temperature at the depth of 200,300 , or it may be 500 feet is accuralely known, while the temperature in the superincumbent strata can only be guessed at. This is the case at the Kentish 'Town well, and partially at Rosebridge and Dukinfield collieries.

It is very desirable that in connection with temperatures at great depths there should in each locality be an accurate obser. vation at the depth of from 50 to Ioo feet. At such depths in the solid ground before it has been disturbed by mining operations, one olservation suffices to give a good approximation to the mean temperature of many years. At depths of two or three feet it is necessary to observe, once a week, or so, throughout a year, in order to gret the mean temperature at that depth for that year; and this may differ by a considerable amount from the mean of a series of years.

In the Report of the Scottish Meteorological Society for the quarter ending December 1862 , there is a comparison of the mean temperature of the air with that of the soil at the depths of 3,12 , and 22 inches, at four stations, from observations extending over five years; and in the Journal of the same society for the quarter ending December i 865 , there is a comparison of the temperature of drained and undrained land from one year's observations, undertaken for this purpose at two stations, and including also a comparison with the temperature of the year. The mean temperattire of the air for each day is, in these comparisons, assumed to be the simple arithmetical mean of the maximum and minimum, as indicated by self-registering thermometers 4 feet from the ground. From these observations, it appears that the mean annual temperature of the soil was in every case rather above that of the air, and that the excess was greater for sand than for unclrained clay, and was greater for drained land than for the same land undrained.

The greatest excess occurred in the case of the 22-inch thermometerat Nookten (Vale of Leven), where both surface and subsoil are sandy and dry. The five yearly means at this station were :--

Air $46^{\circ} \mathrm{I}$; soil at 3 incles $46^{\circ} 3$, at 12 inches $47^{\circ} 3$, at 22 inches $48 \%$; giving an cxcess of 1.9 for the temperature at the depth of 22 inches as compared with air.

The smallest excess, in the case of the 22-inch" thermometers, observed for five years, was at Linton (East Lothian) where it amounted to 0.7 ; but the observations on the effect of drainage gave for the year of observation an excess of only 0.2 at the depth of 30 inches in light sandy but undrained soil under a ryc grass crop, at Otter House near Loch Fyne, the corresponding excess for drained land of the same kind and in the immediate vicinity being 0.9

The mean temperature at the depth of 3 feet at Professor Forbes' three stations at IEdinburgh, from five years' observations, gave an excess of 0.55 above the mean temperature of the air at Edinburgh as deternined by Mr. Adie's observations.

Observations on soil temperature in England are much needed, but the Greenwich observations give an excess of soil above air temperature falling within the limits above quoted, the excess 
at 3 French feet being $I \cdot 7$, while at 24 French feet it is reduced to $\mathrm{r}^{\circ}$. The soil of which the Observatory Hill is composed, and in which the thermometers are sunk, is dry gravel, and the unusual circumstance of decrease of temperature downward observed in the comparison of the 3 feet and 24 feet thermometers, seems to indicate that the surface of the hill is warmer than the surrounding land.

In the present state of our knowledge, then, it appears that when the temperature of the earth has been observed at a deptly of some hundreds of feet in any locality in Great Britain, and has not been accurately determined at a less depth, some lnowledge of the rate of increase downwards may be obtained, by asstuming provisionally that the mean temperature of the surface is about a degree higher than the mean temperature of the air, supposing the latter to be known.

It is to be wished that the Meteorological Society would, from the ample materials in their possession, publish a map of annual isothermals for Great Britain; and the objects of this conmittee would be greatly furthered by an extensive series of soil temperature observations at the depth of about 3 feet.

The committee are anxious to carry into effect $\mathrm{Mr}$. Hull's proposal (quoted in their last Report) to bore down from the bottom of a deep mine; and as Rosebridge Colliery appears to be an eminently suitable locality for such an operation, the Secretary has consulted $\mathrm{Mr}$. Bryliam respecting its practicability and probable cost. Mr. Bryham's reply is that there would be no difficulty in carrying out the proposal at Rosebridge, that to make preparations and bore 300 feet would, on a rough estimate, cost 6150 , and that the second 300 feet would probably cost about the same sum.

The committee would earnestly appeal to the liberality of the Association to enable them to put this design in execution, and they would remark that the sooner it is carried ont, the more valuable the results obtained will be, as the mine has been but recently opened to its present depth, and the influence of atmospheric temperature will every year become more sensible in the strata below.

\section{SCIENTIFIC SERIALS}

In the Amnalen der Chemie und Pharmacie for May 1870, we find several important papers, of which the following are abstracts:- "Investigations on some derivatives of cimnamic acid, by Carl Glaser." In this lengthy and most interesting paper is described the Phenylpropiolic acid $\mathrm{C}_{9} \mathrm{H}_{6} \mathrm{O}_{2}$, a new acid which differs from cimnamic acid by containing $\mathrm{H}_{2}$ less. It is obtained either by the action of sodium and $\mathrm{CO}_{2}$ on $\beta$ bromstyrol; or by the action of alcoholic potash on a bromcinnamic acid. On heating with water to $120^{\circ}$, it splits up into $\mathrm{CO}_{2}$ and acetenylbenzol $\mathrm{C}_{2} \mathrm{H} \mathrm{C}_{6} \mathrm{H}_{5}$, which latter can also be obtained by the abstraction of $2 \mathrm{HBr}$ from dibromstyrol. Silver, copper, and sodium derivatives of this remarkable hydrocarbon are described, from the latter of which, by the action of $\mathrm{CO}_{2}$, the author succeeded in regenerating phenylpropiolic acid. The paper concludes with an account of some $\mathrm{Cl}$ and $\mathrm{Br}$ derivatives of styrol. - "On mercuryditolyl," by E. Dreher and R. Otto. A white crystalline compound obtained by the action of $\mathrm{Na}_{3} \mathrm{Hg}$ on bromtoluol. The authors did not succeed in preparing the corresponding mercury compound from the isomeric brombenzyl. Note on the behaviour of dibenzyl at high temperatures, by the same authors. This compound is split up according to the equation 2 $\left\{\begin{array}{l}\mathrm{CH}_{2} \mathrm{C}_{6} \mathrm{H}_{5} \\ \mathrm{CH}_{2} \mathrm{C}_{6} \mathrm{H}_{5}\end{array}=2 \mathrm{C}_{6} \mathrm{H}_{5} \mathrm{CH}_{3}+\left\{\begin{array}{l}\underset{\text { Toluylen }}{\mathrm{CH} \mathrm{C} \mathrm{C}_{6} \mathrm{H}_{5}} \\ \underset{\mathrm{CH}}{\mathrm{C} \mathrm{H}_{5}}\end{array}\right.\right.$

"Note on the conversion of Thiophenol (Phenylic sulphydrate) into Phenylic disulphide," by the same authors. This is effected by distilling the mercury compound of the former, when it splits up into mercury and the bisulphide, which is probably due to the decomposition taking place at a temperature at which the affinity of $\mathrm{Hg}$ for $\mathrm{S}$ does not yet come into play, since the homologous toluol and benzyl compounds, which require a much higher temperature, give mercuric sulphide and a monosulphide. "On two isomeric pentachlorbenzols and bichlorbenzols-chloride," by R. Otto: A short description of the mode of preparation and properties of the above compounds. The existence of two pentachlorbenzols, which now seems to be placed beyond all doubt, is of great interest, as it is one of the very few facts irreconcileable with Kekule's benzol theory, which does not admit of the existence of more than one.- "On sulphotoluid," by R. Otto and Gruber. Obtained by the action of sulphuric anhydride on toluol._. "On aceto-mercury monomethyl and aceto-mercury monethyl," by R. Otto. These two compounds are prepared by the action of acetic acid on mercuric methide and ethide respectively.

$$
\left.\underset{\mathrm{CH}_{3}}{\mathrm{CH}_{3}}\right\} \mathrm{Hg}+\left\{\begin{array}{l}
\mathrm{CH}_{3} \\
\mathrm{COOH}
\end{array}=\underset{\mathrm{C}_{2} \mathrm{H}_{3} \mathrm{O}_{2}}{\mathrm{CH}_{3}}\right\} \mathrm{Hg}+\mathrm{CH}_{4}
$$

- "On the preparation of organic sulphur compounds by means ot sodic hyposulphite," by the same author. Alcohol heated with. a concentrated solution gives mercaptan; ethylic iodide mercaptan and ethylic sulphide; chlorbenzyl gives benzylic mercaptan and sulphide.- "On diamidonitro phenylic acid, a new derivative of pictic acid," by Peter Griess. This acid is prepared by the reduction of picric acid with ammonic sulphide.-. "On azobenzol sulphuric acid," by P. Griess. A product of the action of hot fuming sulphuric acid on azobenzol. By fusion with potash, phenoldiazobenzol $\mathrm{C}_{12} \mathrm{I}_{10} \mathrm{~N}_{2} \mathrm{O}$ is obtained, which on treatment with ammonic sulphide, is converted into oxyberi zidin $\mathrm{C}_{12} \mathrm{H}_{12} \mathrm{~N}_{2} \mathrm{O}$. - "On ozone and antozone," by C. Engler and $O$ Nasse. In this lengthy paper are described a long scries of experiments, all of which seem to prove conclusively the nonexistence of the third modification of oxygen, called by Schönbein and others antozone, and which the authors prove to be hydric peroxide formed by the oxidation of water, which was present in all those cases where the so-called antozone has been observed by ozone. - "On the constitution of arbutin," by Hugo Schiff. The author considers arbutin to be derived from one atom glycose + one atom hydroquinone $-\mathrm{H}_{3} \mathrm{O}$, and describes a number of acetyl and benzoyl derivatives in support of his views. - "On the action of hypochlorous acid on allylic chloride," by H. v Geyerfell. The author has obtained the compound $\mathrm{C}, \mathrm{H}, \mathrm{OCl}$ by direct addition of the elements of hypochlorous acid to allylic chloride. This on reduction with sodium amalgam yields a liquid, probably allylic alcohol. (?) - "On a new method for the estimation of grape sugar," by Karl Knapp. This method is based on the fact that an alkaline solution of mercuric cyanide is entirely reduced to metallic mercury by grape sugar. By direct experiment it was found that on boiling, $400 \mathrm{mgr}$. $\mathrm{Hg}(\mathrm{CN})_{2}$ are reduced by $100 \mathrm{mgr}$. sugar. The solution is prepared by dissolving Io grm. pure dry $\mathrm{Hg}(\mathrm{CN})_{2}$ in waler, adding $100 \mathrm{cc}$. of a sodic hydrate solution of $\mathrm{I} \cdot \mathrm{r} .5 \mathrm{sp}$. gr., and diluting to $\mathrm{I}, 000 \mathrm{cc}$. Pure grape sugar is prepared by recrystallising the commercial dried at $100^{\circ}$, from absolute alcohol. The ex periment is performed by heating $40 \mathrm{cc}$. of the mercury solutionthis amount corresponds to $100 \mathrm{mgr}$. sugar-to boiling in a porcelain dish, and then adding sugar solution to complete precipitation of the mercury, the end of the reaction being ascertained by placing a drop of the liquid on to a piece of the finest Swedish filter paper, covering a small beaker containing some very strong ammonic sulphide; a brown spot is observed so long as mercury remains in solution. The advantages of this method over Fehling's are, that being equally accurate, the test solution is exceedingly easy to prepare and perfectly stable, a shorter time is required for the estimation, and that the foreign bodies which mask the pure colour of the cuprons oxide are without influence on the reduction of the mercuric cyanide."On some isopropyl compounds," by R. D. Silva. In this notice are described isopropylic succinate, benzoate, nitrite, and nitrate, all prepared by the action of isopropylic iodide on the respective silver salts of the acids.

THE Fournal of Botany, British and Foreign, for September contains a paper by Dr. H. Trimen on Early Icelandic Botany including an account of Rotböll's observations on the new or little-known but rare plants found in Iceland and Greenland, which appears to have been overlooked by Professor Babington in his "Revision of the Flora of Iceland." It was published in 1770, and adds a few species to the number stated by Professor Babington to be indigenous to Iceland. We have also one of Mr. J. G. Baker's careful and useful contributions to British systematic botany, an account of the British dactyloid saxifrages, which he states to form a complete series of varieties from $S$ caspitosa to $S$. hypnooides, without any clearly marked gap at any point between the extremes; and the line of progression substantially straight, very little if at all complicated, as in the case of Rubus, by cross-relationships. The order of sequence is as follows: $1, S$, caspitosa, 2. S, Sernbergii, 3. S, decipient, 